\title{
Dry Eye among Medical Students of Gandaki Medical College, Pokhara, Nepal
}

\author{
Tuladhar $\mathbf{S}^{1^{*}}$, Poudel $\mathbf{B}^{2}$, Shahi $\mathbf{D}^{3}$ \\ 'Associate Professor, 2,3 Ophthalmic Assistant, \\ Department of Ophthalmology, Gandaki Medical College \& Teaching Hospital, Pokhara, Nepal
}

\section{Keywords}

Dry eye disease, Medical students,

Schirmer test.

\section{Corresponding author \\ *Dr Sarita Tuladhar \\ Associate Professor \\ Department of Ophthalmology \\ Gandaki Medical College \& Teaching \\ Hospital, Pokhara, Nepal \\ Email: drtuladharsarita@yahoo.com}

\begin{abstract}
Introduction: Dry eye disease results from decreased tear production, increased evaporation of tears and inflammation. Medical students often have dry eyes due to use of projectors, computers for study and also due to use of mobiles.

Objective: The present study was undertaken to find out dry eye by Schirmer 1 test with local anesthesia and measurement of wetting of Schirmer test strip.

Methods: Schirmer 1 test with anesthesia was performed on 200 medical students from June 1, 2017 to June 1, 2018 after obtaining informed consent and after applying some exclusion criteria. The test was performed by first applying $4 \%$ topical lignocaine and then using Whatman filter paper no 41 and wetting of the filter paper measured after five minutes and time noted.
\end{abstract}

Results: 146 (73\%) Among 200 Students, were males and 54 (27\%) were females. Mean age of patients was $21.73 \pm 1.42$ years. Mild dry eye was seen in $19.5 \%$, moderate in $13 \%$ and severe dry eye in $13.5 \%$ of medical students

Conclusion: Dry eye is one of common ocular disease among medical students.

\section{INTRODUCTION}

Dry eye is a common disease affecting worldwide. Dry eye is defined as a multifactorial disease of tears and ocular surface that results in discomfort, visual disturbance and tear film instability with potential damage to the ocular surface and is accompanied by increased osmolarity of tear film and inflammation of ocular surface according to International Dry Eye Workshop (2007) ${ }^{1}$.

It is a very common condition affecting a significant percentage of the population. Different surveys have estimated the prevalence of dry eye varying between $5 \%$ and $>30 \%$ in various age groups across different countries and worldwide. The estimated number of people affected by dry eye, range from 25 to 30 million all over the world ${ }^{2}$.
Similarly other studies have also shown that dry eye affects $3-34 \%$ of the global adult population ${ }^{3,4}$.

Dry eye disease results from decreased tear production, increased evaporation of tears and inflammation.

Symptoms of dry eye include dryness, discomfort, irritation, itching, fatigue, foreign body sensations, sensitivity to light in eyes, pain, and burning, mucous discharge and tear film alterations caused by tear deficiency and/or increased tear. More severe cases may present as eyes swelling, redness, corneal epithelium damage, and even vision disturbance.

Various methods used to diagnose dry eye disease include Schirmer test, phenol red thread test, tear film break up time (TBUT), tear meniscus height, epithelial staining 
with rose Bengal and lissamine green, tear osmolarity, impression cytology.

Different tests have been shown to have different specificity and sensitivity. Tear osmolarity determination is the most reliable test to diagnose dry eye but is expensive to perform and time consuming. Schirmer test is one such test which is simple to perform and does not require slit lamp or other equipment and can be performed easily in OPD.

Schirmer introduced the test in 1903 and since then it has been modified by many investigators. Schirmer 1 test is the most popular of the variants and is carried out with and without anesthesia. When performed with anesthesia, it measures basic tear secretion and when performed without anesthesia it measures both reflex and basal tear secretions ${ }^{5,6}$.

Gandaki Medical College Teaching Hospital is a tertiary centre at Pokhara with medical students enrolled in different subjects for graduation and post graduation. The MBBS program was started in 2010. Medical students often have dry eyes due to use of projectors, computers for study and also due to use of mobiles. Numbers of students come to Ophthalmology OPD with the problem. So this study is done to screen dry eye among medical students.

\section{MATERIALS AND METHODS}

After obtaining informed consent, 200 medical students from June 1, 2017 to June 1, 2018 were screened for dry eye by Schirmer 1 test after obtaining informed consent. Schirmer 1 test was done by commercially available schirmer strip that is Whatman filter paper no 41. Topical $4 \%$ xylocaine was applied to both the eyes five minutes before the test. Five millimetre of the Schirmer strip was folded and kept at the junction of lateral one third and medial two third of the lower eye lids with the eyes open. After five minutes the strip was removed and wetting of the strip was measured. According to wetting of the Schirmer strip, dry eye was graded as normal when the reading is more than $15 \mathrm{~mm}$, mild dry eye $11-15 \mathrm{~mm}$, moderate dry eye 5 - $10 \mathrm{~mm}$, and severe less than $5 \mathrm{~mm}$.

\section{RESULTS}

Among 200 students who were screened for dry eyes, 146 were males and 54 were females. The mean age of the students was $21.73 \pm 1.42$ years. Table 1 shows age and sex distribution of the patients.

Table 1: Age and sex distribution of patients

\begin{tabular}{ccc} 
Age & Males & Females \\
18 & 2 & 1 \\
19 & 6 & 3 \\
20 & 20 & 4 \\
21 & 34 & 19 \\
22 & 33 & 13 \\
23 & 39 & 12 \\
24 & 7 & 0 \\
25 & 5 & 2 \\
Total & $146(73 \%)$ & $54(27 \%)$ \\
\hline
\end{tabular}

Schirmer test showed that 108 students were normal that is there are no dry eyes, and 39 students had mild dry eyes, 26 students had moderate dry eyes and 27 had severe dry eyes.

Table 2: The results of Schirmer test

\begin{tabular}{lcc}
\hline & No. of patients & Percentage (\%) \\
Normal & 108 & $54 \%$ \\
Mild dry eye & 39 & $19.5 \%$ \\
Moderate dry eye & 26 & $13 \%$ \\
Severe dry eye & 27 & $13.5 \%$ \\
\hline
\end{tabular}

\section{DISCUSSION}

Dry eye is seen in all age groups but more commonly occurs in adult population. Dry eye is especially more common in those who work in computers, visual display terminals. No such studies among medical students have been done. Medical students are prone to dry eye due to prolonged use of projectors and computers for their academic activity. Also use of mobiles is common in this age group.

Dry eye is more common in females compared to males in studies done world wide ${ }^{7,8,9,10}$. Also study by Suchi Shah and Harsha Jani showed that $52 \%$ females had dry eyes compared to males ${ }^{11}$.

Likewise a retrospective study conducted at Miami and Broward Veterans Affairs Eye Clinics estimated a prevalence of $22 \%$ DED in females compared to $12 \%$ in males ${ }^{12}$. In our study, it is more common among males than females. This can be explained from the fact that majority of the students were males. Also dry eyes in common among elderly women in studies world-wide but in our studies the subjects were 
in twenties.

Our studies showed that $46 \%$ of the students had dry eyes, and $13.5 \%$ had severe dry eyes. Various hospital based studies showed prevalence of dry eyes as $18.4 \%$ and $40.8 \%{ }^{13,14,15}$. Similarly the prevalence of dry eye is $25 \%$ in Canada ${ }^{16}$ and $33 \%$ in Japan $^{17}$.

Dry eye has been seen among computer users. A study by Sandip D. Patil et $a l^{18}$ among computers showed that dry eye is seen among $25 \%$ computers users. Study of medical students is generally based on computers and lap tops, so the dry eye seen among our students is consistent with other studies.

\section{CONCLUSION}

Dry eye is one of common ocular disease among medical students. Knowledge of dry eye helps in early diagnosis and treatment of dry eyes.

\section{REFERENCES}

1. International Dry eye Disease Workshop (DEWS). The definition and classification of dry eye disease: Report of the Definition and Classification Subcommittee of the International Dry Eye Workshop. Ocul Surf. 2007; 5: 75-9.

2. Phadatare SP, Momin M, Nighojkar $\mathrm{P}$, et al. A comprehensive review on dry eye disease: Diagnosis, medical management, recent developments, and future challenges. Advances in Pharmaceutics. 2015; 2015: Article ID 704946.

3. Cleegg J.P, Guest JF, Lehman A, et al. The annual cost of dry eye syndrome in France, Germany, Italy, Spain, Sweden and the United Kingdom among patients managed by ophthalmologists. Ophthalmic Epidemiol. 2006; 13: 263-274.

4. The epidemiology of dry eye disease: Report of the epidemiology subcommittee of the International dry eye workshop. Ocul Surf. 2007; 5: 93-107.

5. Savini G, Prabhawasat P, Kozima T, et al. The challenge of dry eye diagnosis. Clin Ophthalmol. 2008; 2(1): 31-35.
6. Smith J, Nichols KK, Baldwin EK. Current patterns in the use of diagnostic tests in dry eye evaluation. Cornea. 2008; 27(6): 656-662.

7. Johnny L Gayton. Etiology, prevalence, and treatment of dry eye disease. Clinical Ophthalmology. 2009; 3: 405-412.

8. Schaumberg DA, Sullivan DA, Buring JE, et al. Prevalence of dry eye syndrome among US women. Am J Ophthalmol. 2003; 136: 318-326.

9. Moss SE, Klein R, Klein BE. Prevalence of and risk factors for dry eye syndrome. Arch Ophthalmol. 2000; 118: 1264-1268.

10. Lin PY, Tsai SY, Cheng CY, et al. Prevalence of dry eye among an elderly Chinese population in Taiwan: The Shihpai eye study. Ophthalmology. 2003; 110: 1096-1101.

11. Suchi Shah and Harsha Jani. Prevalence and associated factors of dry eye: Our experience in patients above 40 years of age at a Tertiary Care Center. Oman J Ophthalmol. 2015 Sep-Dec; 8(3): 151-156.

12. Galor A, Feuer W, Lee DJ, et al. Prevalence and risk factors of dry eye syndrome in a United States veterans affairs population. Am J Ophthalmol. 2011; 152: $377-84$.

13. Sahai A, Malik P. Dry Eye: Prevalence and attributable risk factors in a Hospital based population. Ind J Ophthol. 2005; 53: 87-91.

14. Gupta N, Prasad I, Jain R, et al. Estimating the prevalence of dry eye among Indian patients attending tertiary ophthalmology clinic. Ann Trop Med Parasitol. 2010; 104: 247-255.

15. Basak SK, Pal PP, Basak S, et al. Prevalence of dry eye diseases in Hospital-based population in West Bengal, Eastern India. J Indian Med Assoc. 2012; 110: 789-794.

16. Doughty MJ, Fonn D, Richeter D, et al. A patient questionnaire approach to estimating the prevalence of dry eye symptoms in patient presenting to optometric practices across Canada. Optom Vis Sci. 1997; 74: 624-631. 
Original Article | Journal of Gandaki Medical College-Nepal

17. Shimmura S, Shimazaki J, Tsubota K. Results of a population-based questionnaire on the symptoms and lifestyles associated with dry eye. Cornea. 1999; 18: 408-411.

18. Sandip D. Patil, Harish R. Trivedi, et al. Evaluation of dry eye in computer users. Int J Community Med Public Health. 2016 Dec; 3(12): 3403-3407. 